\title{
Games and simulation in higher education
}

Angel A. Juan ${ }^{1 *}$, Birgit Loch ${ }^{2}$, Thanasis Daradoumis ${ }^{3}$ and Sebastian Ventura ${ }^{4}$

* Correspondence: ajuanp@uoc.edu 'Open University of Catalonia - IN3, Barcelona, Spain

Full list of author information is available at the end of the article
Keywords: Gamification; Higher education; Games; Simulation

The evolution of computer technologies, together with the increasing speed of Internet-based communications, has promoted the use of simulation software and serious games in higher education. These technological and methodological tools can significantly enrich the learning experience in almost any knowledge area. In particular, they will have a significant impact on how the learning process is performed in the so called Science, Technology, Engineering, and Mathematics (STEM) education. This thematic series brings together several articles related to the use of serious games and simulations in higher education. Technological and pedagogical characteristics of these innovative learning tools are explored through this series, alongside their cultural, technological, and/or social contexts. Among others, the selected articles explore topics such as: (i) the benefits of teaching practices, based on the utilisation of games and simulations, for institutions, professors, and students; (ii) the use of video games and apps to increase student engagement, retention, and academic achievement; (iii) the enrichment of simulation-based learning scenarios by the incorporation of the tactile experience to the more traditional visual and hearing ones; (iv) the use of adapted virtual learning environments that simulate real-life environments; and (v) the analysis of collaborative intergenerational interaction throughout digital games. In our view, the use of games and simulation in higher education is yet in its early stage, but thanks to the current state of these technological tools and to the high degree of acceptance among the new generations of students and instructors, it seems quite evident to us that their increasing incorporation in higher education systems around the world is just a question of time. A short description of each of the selected articles is provided next:

In "The effect of games and simulations on higher education: a systematic literature review", Vlachopoulos and Makri offer a survey on the use of games and simulations as innovative teaching methods in higher education. They analyze how games and simulations allow instructors to better achieve specific learning objectives. According to their study, these teaching methodologies have a positive impact on cognitive, behavioural, and affective aspects of students during the learning process. Also, the pedagogical benefits for academics and practitioners in higher education are highlighted in this work. 
The paper "Using a gamified mobile app to increase student engagement, retention and academic achievement", by Pechenkina et al., evaluates the effectiveness of a gamified mobile app as a learning tool. Thus, they investigate the potential influence of using such an app on students' academic performance and their engagement in the subject. The authors employ an app to deliver multiple-choice content-based quizzes directly to students' personal mobile devices. After measuring the relationships between students' app usage and their engagement, retention, and academic achievement in the subject, they show that all these measures are positively correlated with the app usage. The authors also highlight the benefits of using apps to customise content related to a specific course, the ease of use and general flexibility of these learning tools, and the automated collection of the app usage analytics.

In "A quantitative approach to pre-service primary school teachers' attitudes towards collaborative learning with video games: previous experience with video games can make the difference", Martín del Pozo et al. analyze the attitudes of pre-service primary school teachers towards collaborative learning with video games. The paper investigates whether these attitudes are influenced by factors such as: (i) the years of experience in playing video games of each pre-service teacher; (ii) the frequency at which he/she plays; and (iii) his/her gender. The results of a Likert-based survey with over 190 participants indicate that the interviewed teachers have a positive attitude towards collaborative learning with video games. The study also shows that those who have played video games for more years, who play more frequently, and who are male tend to have more positive attitudes towards the use of video games in collaborative learning activities.

The article 'Undergraduate students' conceptual interpretation and perceptions of haptic-enabled learning experiences", by Shaikh et al., studies the potential of haptic technologies in supporting conceptual understanding of difficult scientific concepts. Their study identified: (i) how students with different background conceptually interpreted the tactile learning experience; and (ii) students' perceptions on the use of haptic technologies for their learning. The results of a pretest-posttest study show that students significantly improved their conceptual understanding after being exposed to a haptic-enabled learning experience. Also, students agreed that they considered this learning experience as both usefulness and easy-to-interact with.

In "Scenarios in virtual learning environments for one-to-one communication skills training", Lala et al. explores the characteristics of interaction scenarios, between a player and a virtual character, in a learning context that simulates real-world communication experiences. They also provide a literature review and a classification of these one-to-one interaction scenarios, based on characteristics such as: structure, properties, and parameters. The authors present RAGE, a configurable authoring tool to create a scenario. This tool can be used to construct scenarios for various applied games, including a job-seeker game to practice interview skills at an employment agency and a student game to practice a business negotiation.

Finally, the article "Situated learning through intergenerational play between older adults and undergraduates", by Zhang et al., uses conversation analysis to examine the talk-in-interaction of conversations between older adults and undergraduates during several weeks of intergenerational digital gameplay. The interactional connection between the two age groups is analyzed in the context of situated learning. The study explains the relationships between the two age groups and demonstrates how older 
adults can participate in collaborative activity supported by situated instruction from younger people. The findings highlight the potential of using digital games to engage older adults and younger people in meaningful interactions.

All in all, the Guest Editors of this thematic series expect that this selection of articles is of interest for the readers of the Int. J. of Educational Technology in Higher Education and contributes to push forward the use of games- and simulation-related practices in higher education as well as the research on this emerging and interdisciplinary area combining computer-based learning techniques, human-computer interaction, and pedagogical methods.

Authors' contributions

All authors read and approved the final manuscript.

Competing interests

The authors declare that they have no competing interests.

\section{Publisher's Note}

Springer Nature remains neutral with regard to jurisdictional claims in published maps and institutional affiliations.

Author details

'Open University of Catalonia - IN3, Barcelona, Spain. ${ }^{2}$ La Trobe University, Bundoora, Australia. ${ }^{3}$ University of the Aegean, Mytilene, Greece. ${ }^{4}$ University of Cordoba, Cordoba, Spain.

Received: 28 September 2017 Accepted: 28 September 2017

Published online: 09 October 2017

\section{Submit your manuscript to a SpringerOpen ${ }^{\circ}$ journal and benefit from:}

- Convenient online submission

- Rigorous peer review

- Open access: articles freely available online

- High visibility within the field

- Retaining the copyright to your article

Submit your next manuscript at $>$ springeropen.com 